\title{
Discussion on determination method of unslaked lime activity for dry flue gas desulfurization
}

\author{
Wangtaoying $^{1}$, Xujunfeng ${ }^{1}$, Jihaihong ${ }^{1}$, Zhangchao $^{1}$, Zhangyao $^{1}$, Boyang ${ }^{1}$ \\ ${ }^{1}$ Huadian Electric Power Research Institute Co., Ltd., Hangzhou, Zhejiang, china
}

\begin{abstract}
When measuring the activity of unslaked lime by "DL/T 323-2010 method for determining the activity of unslaked lime for dry flue gas desulfurization", it was found that different results of unslaked lime activity were obtained by placing thermometers at different positions in thermally insulated container. The improvement measures of the shape of thermally insulated container, the position of thermometer, the position of stirrer and the sample injection equipment were put forward. The improved experimental equipment and method showed that the activity data of quicklime had a good reproducibility at $\pm 1{ }^{\circ} \mathrm{C}$. The data detected by the improved experimental method can be of great significance to production.
\end{abstract}

\section{Introduction}

The main ways to reduce $\mathrm{SO}_{2}$ concentration in flue gas of thermal power plants are fuel desulfurization, combustion desulfurization and post-combustion desulfurization (flue gas desulfurization). Flue gas desulfurization will not affect the combustion and heat transfer in the furnace, so it is the most effective method to control $\mathrm{SO}_{2}$ pollution at present. Flue gas desulfurization process is divided into dry, semi-dry and wet desulfurization.

Dry flue gas desulfurization is to remove $\mathrm{SO}_{2}$ by chemical reaction by adding powder or granular absorbent, or catalyst into furnace or flue gas. For example, the circulating fluidized bed dry flue gas desulfurization technology uses unslaked lime as an absorbent and reacts with $\mathrm{SO}_{2}$ in flue gas under certain temperature and humidity conditions to generate $\mathrm{CaSO}_{3}$ and $\mathrm{CaSO} 4$ to fix $\mathrm{SO}_{2}$ in flue gas.

The quality of unslaked lime is measured by "activity", which reflects the reaction ability with other substances. The methods for measuring the activity of quicklime include hydrochloric acid titration and temperature rise rate method. Hydrochloric acid titration is greatly influenced by the amount of indicator and titration rate. The temperature rise rate method, also known as the hydrolysis temperature rise method, is used to reflect the strength of the activity degree by the temperature rise rate of calcium oxide when dissolved in water, and the activity is evaluated and expressed by the ratio of the maximum temperature rise to the required time of quicklime digestion under specified conditions.

\section{The experiment}

The requirement of dry flue gas desulfurization process for unslaked lime is that the time needed for the temperature to rise to $60^{\circ} \mathrm{C}$ in the reaction of quicklime with water is less than 4 minutes .

\subsection{According to the "DL/T 323-2010 method for determining the activity of unslaked lime for dry flue gas desulfurization", the experimental process is as follows.}

- Prepare $1 \mathrm{~kg}$ of $1 \mathrm{~mm} \sim 2 \mathrm{~mm}$ unslaked lime samples, mix them evenly and then put them in a dry airtight container for later use.

- The laboratory maintained a constant temperature of $20{ }^{\circ} \mathrm{C} .1000 \mathrm{~mL}$ distilled water or deionized water was taken from a beaker and placed in a water bath. The temperature was maintained to $20{ }^{\circ} \mathrm{C} \pm 0.5^{\circ} \mathrm{C}$.

- Take $600 \mathrm{~mL}$ of constant temperature distilled water or deionized water and inject it into an thermally insulated container. Start the agitator and rotate it at the speed of $300 \mathrm{r} / \mathrm{min} \pm 50 \mathrm{r} / \mathrm{min} .150 .0 \mathrm{~g}$ of unslaked lime sample was immediately added to the water and the time was started. Temperature data was recorded every $20 \mathrm{~s}$. When the activity of quicklime is strong, readout interval can be adjusted appropriately.

- Continuous reading is completed until the temperature change of the three adjacent readings is less than $0.5^{\circ} \mathrm{C}$. Take the time of the first reading of the last three adjacent readings as $t$, and the temperature at this time is $\mathrm{T}_{\max }$.

- The calculation formula is $A=\left(T_{\max }-T_{0}\right) / t$.

- Schematic diagram of measuring device: 


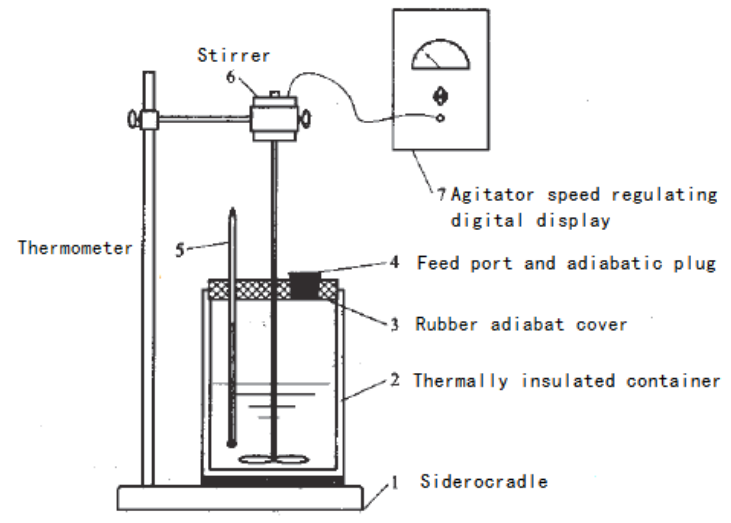

Fig.1 Schematic diagram of unslaked lime measuring equipment

\subsection{Contrast experiment}

The placement of the thermometer was not specified in the experiment. Two groups of experiments were conducted. One group placed the thermometer near the adiabatic vessel wall, and the other group placed the thermometer as close as possible to the agitator. The experiments were as follows:

2.2.1 For the first set of experiments, place the thermometer near the adiabatic vessel wall and follow the experimental steps of DL/T 323-2010. Data results are shown in table 1:

Table 1 Thermometers placed near the adiabatic vessel wall were used to measure the activity of unslaked lime

\begin{tabular}{c|ccccccccc}
\hline time $(\mathrm{s})$ & 0 & 15 & 20 & 30 & 40 & 50 & 60 & 80 & 90 \\
\hline temperature $\left({ }^{\circ} \mathrm{C}\right)$ & 19.6 & 24.45 & 28 & 32 & 38 & 42 & 46 & 52 & 56 \\
\hline time $(\mathrm{s})$ & 100 & 110 & 120 & 130 & 140 & 150 & 160 & 170 & 180 \\
\hline temperature $\left({ }^{\circ} \mathrm{C}\right)$ & 58 & 60.8 & 64.3 & 65 & 65.5 & 66.0 & 66.0 & 66.0 & 65.5 \\
\hline
\end{tabular}

As shown in figure 2 for temperature rise diagram:

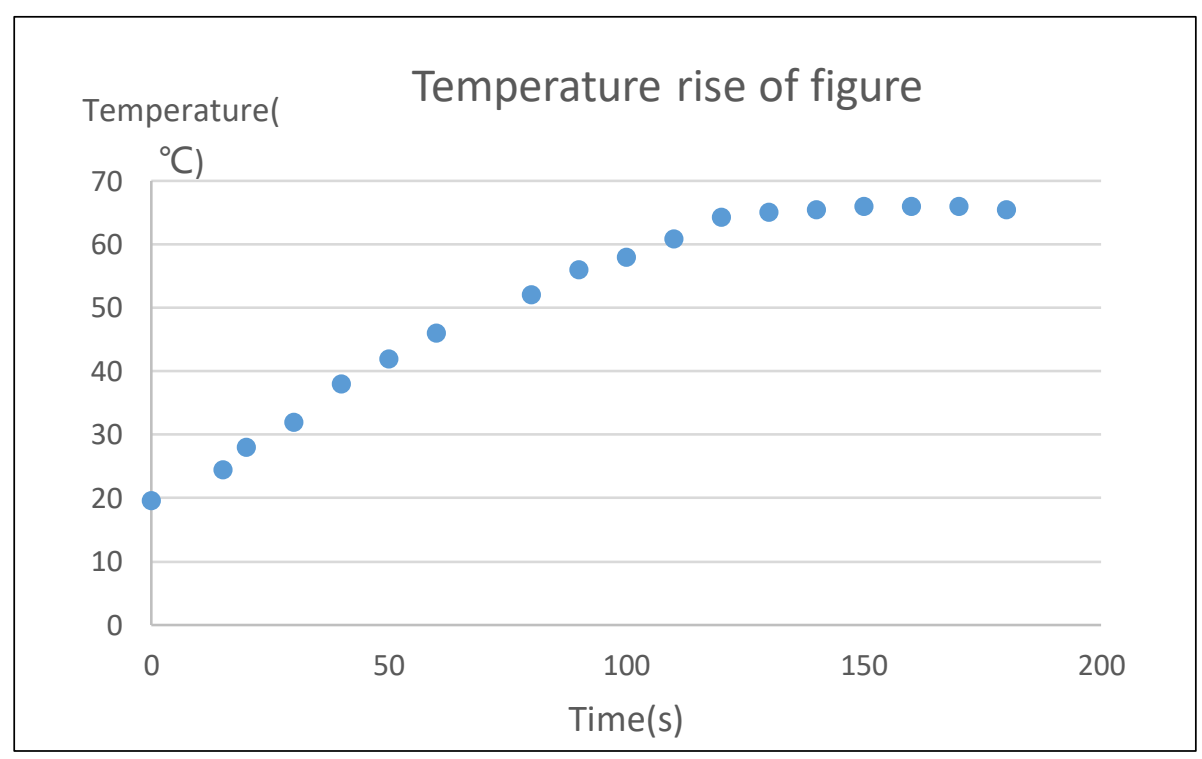

Fig.2 Temperature rise of figure of thermometers are placed near the adiabatic vessel walls to measure the activity of unslaked lime

2.2.2 In the second group of experiments, place the thermometer as close as possible to the agitator, and follow the experiment steps of DL/T 323-2010. Data results are shown in table 2:

Table 2 Thermometer placed as close as possible to the agitator near the lime activity test data

\begin{tabular}{cccccccccc}
\hline time $(\mathrm{s})$ & 0 & 12 & 20 & 30 & 40 & 50 & 60 & 70 & 80 \\
\hline temperature $\left({ }^{\circ} \mathrm{C}\right)$ & 20.3 & 40.6 & 46.8 & 50.7 & 56.9 & 61.2 & 66.2 & 70.9 & 74.7 \\
\hline time $(\mathrm{s})$ & 110 & 120 & 130 & 140 & 150 & 160 & 170 & 180 & 190 \\
\hline temperature $\left({ }^{\circ} \mathrm{C}\right)$ & 84.2 & 86.3 & 87.8 & 89.4 & 90.1 & 90.9 & 91.6 & 91.9 & 92.1 \\
\hline
\end{tabular}

As shown in figure 3 for temperature rise diagram: 


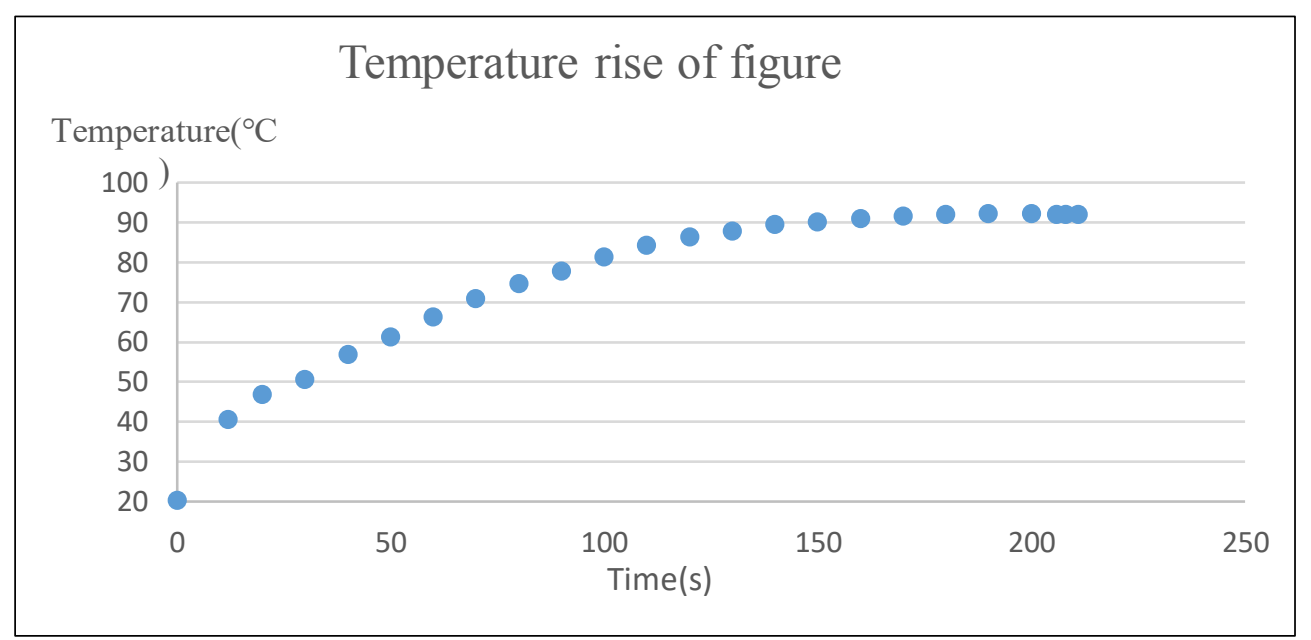

Fig.3 Temperature rise of figure of thermometer should be placed as close as possible to the agitator to measure the activity of unslaked lime

\subsubsection{Other experimental phenomena}

After the end of the experiment, it was found that there was unslaked lime at the bottom of the beaker which was still exothermic. A thermometer was inserted into the quicklime and the temperature was $89^{\circ} \mathrm{C}$. The volume of unreacted unslaked lime at the bottom of the thermally insulated container was reduced by a third to a quarter when the cylindrical adiabatic vessel was replaced with a spherical one and stirred at the same rate.

\section{Experimental analysis}

- The reaction amount of unslaked lime has a certain relationship with the shape of thermally insulated container. The reaction amount ofunslaked lime with smooth bottom or slender capacity is more than that of general shape.

- According to the above experimental data, the temperature difference of $160 \mathrm{~S}$ between the thermally insulated container wall and the temperature near the agitator is $24.9{ }^{\circ} \mathrm{C}$. The influence of the location of the thermometer far exceeds that of whether the vessel is adiabatic or not. The unslaked lime near the agitator can be fully mixed with water and the reaction is quite complete. The thermometer placed in this position can measure the heat released in time.

- The injection port of the experimental device is small, and when the funnel is used for injection, the unslaked lime will block the funnel port, making it difficult for injection. The improved measure is to fold the paper into the shape of a cylinder and slide the sample along the paper into the thermally insulated container, which can reduce the probability of quicklime clogging and increase the speed of adding the sample obviously.

- When thermometers are close to the agitator, the measured data are easy to reach the desulfurization standard of quick lime, which takes less than 4 minutes to rise to $60{ }^{\circ} \mathrm{C}$. A uniform location of thermometers should be established.

\section{Improvement measures of lime activity test equipment}

- Change the thermally insulated container to a 1000 $\mathrm{mL}$ circular thermally insulated container, or change the thermally insulated container to a $1000 \mathrm{~mL}$ slender cylindrical bottom, such as the bottom diameter of about $70 \mathrm{~mm}$ and height of about 260 . This is conducive to the full stirring of unslaked lime.

- Design the injection device of unslaked lime. A vibrating injection device is set on the injection port to rapidly add unslaked lime to the container.

- The adoption of digital thermometer can improve the recording accuracy of data and reduce the collision damage between agitator and thermometer.

- Position the agitator at the center, place the thermometer at $1 / 2$ of the diameter, and the bottom position is the same plane as the bottom of the agitator.

- The stirring speed can be adjusted to $350 \mathrm{r} / \mathrm{min} \pm$ $50 \mathrm{r} / \mathrm{min}$.

- The improved lime activity test device was used for the test, which showed that the temperature data repeatability was $\pm 1{ }^{\circ} \mathrm{C}$ at $160 \mathrm{~S}$.

\section{References}

1. Liu Liquan, Method for determination of lime activity for dry desulfurization[J]. China's environmental protection industry, 2004(4):34.

2. Kangdan,Yuyu,Feng zhiyun,Etc.Method for determination of oxidefree calcium oxide in unslaked lime :china, $100526862 \mathrm{C}[\mathrm{P}], 2009$.

3. DL/T 323-2010 Method for determination of lime activity for dry desulfurization: $1 \sim 2$. 
4. YE Xiangdong, ZHAO He, LUO Faqing, et al. A long blade cooling system of low pressure cylinder based on the exhaust port: ZL 20172 0604163.X[P]. 2017-12-26[2018-01-22].

5. HU Yongan.Optimization design of calcining process of reactive calcium oxide rotary kiln[J].Anqing normal university:Journal of natural.2010,16(3):76-77;84.

6. ZEN Yanyan.Mathematical description and analysis of the structural characteristics of calcium oxide[J].Journal of Beijing jiaotong university,2006,30(1):107-110.

7. ZHANG Weidong,Building industry standards:Improvement of determination method of calcium oxide in building lime.Standard measurement and quality, 1998,31(3):38. 